\title{
UN ANÁLISIS SOBRE GESTIÓN CUIDADO Y EL ENTORNO DE ENFERMERÍA
}

\author{
An analysis on care management and the nursing environment
}

\author{
Mg. Luisa Pacheco Villa García ${ }^{1}$ \\ ${ }^{1}$ Coordinadora de Centro Quirúrgico Hospital Regional de Ica Ica , Perú \\ Editor Asociado de la Revista Enfermería a la Vanguardia Ica, Perú
}

\begin{abstract}
El cuidado de enfermería requiere conocimiento de múltiples factores del entorno en el que se sitúa la acción de gestión y de las personas que otorgan cuidados. Es indudable que con los cambios en la organización de la salud, las instituciones de salud se han vuelto más complejas. Las restricciones financieras, el déficit de enfermeras, de insumos para la atención en salud, los altos costos, las condiciones de la práctica, la normatividad excesiva, la legislación, las exigencias de los usuarios con mayor nivel de educación e información, así como los cambios demográficos y epidemiológicos en salud, caracterizan hoy el entorno en el que se otorgan los cuidados. Todos estos aspectos constituyen un gran desafío para la práctica y la gestión del cuidado de enfermería.
\end{abstract}

La gran parte de las enfermeras trabajamos en centros hospitalarios, centros comunitarios y universitarios que se encuentran administrados con un sistema muy complejo, y excesiva división de tareas. Por otro lado existen grupos de poder, los jefes, los médicos, los sindicatos y diversos grupos profesionales, lo cual genera algunos problemas en relación al reconocimiento, estatus, comunicación, autonomía y responsabilidad, que pueden complicar las actividades para una gestión del cuidado adecuado.

Al interior de los propios departamentos de enfermería, existen elementos que obstaculizan el entorno para una gestión efectiva tales como: personal escaso, con predominio femenino enfrentado a múltiples roles sociales (esposa, madre, profesionista), rotación de personal por necesidad no toman en cuenta las especialidades que han estudiado, ausentismo, equipos de trabajo muy heterogéneos en su formación, con un déficit de educación continua, con una cultura profesional débil de ayuda, diferentes tipos de contratos laborales y por ende diferentes beneficios servicio y altruismo; que además debe hacer frente a situaciones de estrés, angustia y dolor de los pacientes. En fin, un personal responsable del cuidado que trabaja en un medio ambiente altamente complejo y donde surgen en algunas ocasiones dilemas éticos. Desde esta perspectiva del entorno la gestión del cuidado requiere de la enfermera jefe, el ejercicio del liderazgo y la motivación, dos procesos esenciales para garantizar un cuidado de calidad. El liderazgo permite influir en la acción de las personas responsables del cuidado en relación a su compromiso personal y de respeto a las personas, así, la enfermera que realiza gestión puede transmitir los valores del cuidado y asumir actitudes de apoyo para con el personal responsable del mismo y reducir los factores que obstaculizan un cuidado de calidad.

La enfermera que realiza gestión debe tener entonces el compromiso de generar un clima de trabajo favorable y participativo con dominio y equilibrio de inteligencia emocional, debe hacer participar al personal en las decisiones, pedir la opinión del grupo, ser receptiva ante las demandas del personal, reconocer el trabajo, compartir la información, favorecer la creatividad, promover el espíritu de equipo, fomentar la autonomía y la capacitación de todos los miembros del grupo de cuidados. La motivación del personal responsable del cuidado es esencial a fin de lograr un entorno propicio para el cuidado. Una enfermera satisfecha y estimulada por su trabajo será capaz de comprometerse en 
mejorar la calidad de los procesos de cuidado dirigidos a favorecer el confort, la comunicación, la curación y a promover la salud de las personas que cuida.

La gestión de los cuidados debe estar orientada hacia la persona, el cliente, su familia, el personal de enfermería, los equipos interdisciplinarios. La gestión se identifica como un proceso humano y social que se apoya en la influencia interpersonal, del liderazgo, de la motivación y la participación, la comunicación y la colaboración. Utilizando el pensamiento enfermero, la enfermera que realiza gestión debe favorece una cultura organizacional centrada en el cuidado de la persona. 